Annuaire suisse de politique de développement

12 | 1993

Annuaire Suisse - Tiers Monde 1993

\title{
Les investissements directs de la Suisse à l'étranger
}

Die schweizerischen Direktinvestitionen im Ausland

Catherine Marrel

\section{OpenEdition}

\section{Journals}

Édition électronique

URL : http://journals.openedition.org/aspd/1432

DOI : $10.4000 /$ aspd. 1432

ISSN : 1663-9669

\section{Éditeur}

Institut de hautes études internationales et du développement

\section{Édition imprimée}

Date de publication : 1 février 1993

Pagination : 225-241

ISSN : 1660-5934

\section{Référence électronique}

Catherine Marrel, «Les investissements directs de la Suisse à l'étranger », Annuaire suisse de politique de développement [En ligne], 12 | 1993, mis en ligne le 30 avril 2013, consulté le 08 septembre 2020 URL : http://journals.openedition.org/aspd/1432 ; DOI : https://doi.org/10.4000/aspd.1432

Ce document a été généré automatiquement le 8 septembre 2020

(c) The Graduate Institute I Geneva 


\title{
Les investissements directs de la Suisse à l'étranger
}

Die schweizerischen Direktinvestitionen im Ausland

\author{
Catherine Marrel
}

\section{NOTE DE L'ÉDITEUR}

En français, résumé seulement. Lire l'article original en allemand dans Schweizerisches Jahrbuch für Entwicklungspolitik : « Die schweizerischen Direktinvestitionen im Ausland », http://sjep.revues.org/1251.

\section{RÉSUMÉS}

Die Entwicklung der schweizerischen Direktinvestitionen folgte im Grossen und Ganzen den internationalen Tendenzen. Zwischen 1985 und 1991 verdoppelte sich das Direktinvestitionskapital im Ausland. Dabei gewannen die Investitionen der Dienstleistungsunternehmen immer mehr an Gewicht.

Die Direktinvestitionsflüsse siedelten sich grösstenteils in den Industrieländern an, wo sich auch die wichtigsten Handelspartner der Schweiz befinden. In der ersten Hälfte der 80erJahre erfuhren die Kapitalexporte in die USA einen grossen Aufschwung. Seit 1987 verlagerten die Unternehmen das Schwergewicht ihrer Direktinvestitionen nach Europa. Die Direktinvestitionsflüsse in die Entwicklungsländer verloren an Bedeutung. Die durch Schulden und stagnierende Rohstoffpreise aber auch durch politische Instabilität geprägten Binnenmärkte der Entwicklungsländer vermochten immer weniger ausländische Unternehmen anziehen. Erst in der jüngsten Zeit scheinen die schwersten politischen und wirtschaftlichen Hypotheken überwunden. Seit 1990 scheinen die strukturellen Reformen einschliesslich 
Handelsliberalisierung, Privatisierung und Deregulierung der Märkte sowie die verstärkte Öffnung zum Aussenhandel sich in einer Belebung der Direktinvestitionsflüsse in die Entwicklungsländer auszuwirken.

Une statistique des investissements directs de la Suisse existe depuis 1985. L'auteur présente d'abord le contenu du relevé, sa méthode et la définition d'investissement direct sur laquelle elle se fonde. Elle passe ensuite à une description des principales tendances révélées par l'évolution des données recueillies. On constate notamment que, dans la période 1985-1991, le montant des investissements directs totaux a presque doublé, en passant à environ 100 milliards de francs, la part destinée au Tiers Monde (Caraïbes et Panama exclus) ayant glissé en-dessous de $10 \%$. Les deux tiers de cette part sont par ailleurs concentrés sur un petit nombre de "nouveaux pays industrialisés ». Dans le flux d'investissements vers les pays riches, l'Europe a relayé les EtatsUnis en tant que principal pôle d'attraction. Quant à la répartition selon les secteurs, la tendance générale a été de privilégier les services plutôt que l'industrie. Dès 1991, on dispose pour la première fois de la ventilation selon les régions des revenus réinvestis : dans le Tiers Monde, cette source de financement couvrait environ la moitié du total des investissements tandis que dans le reste du monde la proportion correspondante ne représentait que $10 \%$. En 1991, l'ensemble des entreprises suisses à l'étranger occupait environ un million de personnes, soit $17 \%$ dans le Tiers Monde dont les deux tiers dans les « nouveaux pays industrialisés ». Le détail des chiffres est réuni dans le tableau 1 (flux des investissements), le tableau 2 (source des flux des investissements pour 1991), le tableau 3 (montant des investissements) et le tableau 4 (nombre de personnes occupées).

\section{AUTEUR}

\section{CATHERINE MARREL}

Wissenschaftliche Mitarbeiterin, Schweizerische Nationalbank. 